\title{
Dissociation of chronic vascular cell proliferation and vascular contractility after chronic cigarette smoke exposure
}

\author{
J.L. Wright, J-P. Sun
}

\begin{abstract}
Dissociation of chronic vascular cell proliferation and vascular contractility after chronic cigarette smoke exposure. JL. Wright, J-P Sun. (C)ERS Journals Ltd 1999.

ABSTRACT: In guinea pigs, chronic cigarette smoke exposure produces physiological and structural alterations in the pulmonary vasculature via unknown mechanisms. This study aimed to determine whether chronic cigarette smoke exposure can induce altered pulmonary vascular reactivity, and whether chronic smoke exposure would be associated with a continued increase in vascular cell deoxyribonucleic acid (DNA) synthesis, indicative of cell proliferation. Guinea-pigs were therefore exposed to two regimens of smoke.

In the first experiment, animals were exposed once to the smoke of seven cigarettes, and sacrificed $24 \mathrm{~h}$ post-smoke, while in the second experiment, the guinea-pigs were exposed for 5 days each week for 4 months. Control animals were exposed to air. Lung explant preparations and computer linked image photography were utilized to determine vascular reactivity, and DNA synthesis was assessed using the 5-bromo-2'deoxyuridine technique.

Neither acute nor chronic smoke exposure affected vascular reactivity, although the older animals had lesser reactivity. In the chronically smoked animals, evidence was found of ongoing vascular DNA synthesis, and evidence of structural alterations with increased muscularization of the arterioles $(34.7 \pm 7.6 \%$ of arterioles in control versus $62.7 \pm 5.5 \%$ after smoke exposure).

Despite evidence of continued deoxyribonucleic acid synthesis in the peribronchiolar vessels, the alterations of vascular physiology previously found in this model cannot be ascribed to increased reactivity at this site. Instead, the chronic deoxyribonucleic acid synthesis in the arterioles adjacent to the alveolar ducts, culminating in an increased number of fully muscularized vessels, would suggest this compartment as the most probable source.
\end{abstract}

Eur Respir J 1999; 14: 832-838.

Dept of Pathology, University of British Columbia, Canada.

Correspondence: J.L. Wright

Dept of Pathology

2211 Wesbrook Mal

Vancouver, B.C.

V6T 2B5 Canada

Fax: 6048227104

Keywords: Cigarette smoke pulmonary hypertension

Received: November 161998 Accepted after revision May 171999

Supported by grants from Heart and Stroke Foundation of B.C. and Yukon
The association of pulmonary hypertension and chronic airflow obstruction in cigarette smokers is well documented, although its pathogenesis is controversial, and probably has a multifactorial basis. Suggested aetiologies include vascular bed destruction secondary to emphysema [1], hypoxia (either systemic or pulmonary) induced vasoconstriction $[2,3]$ and alteration of the arterial structure with either increased vascular tone, or increased resistance to flow due to a distorted vessel wall [3]. To investigate these possible aetiologies, an animal model was developed in which guinea-pigs were chronically exposed to cigarette smoke. It was found that the smoke exposed animals developed emphysema, airflow obstruction and elevated pulmonary arterial pressure in the absence of systemic hypoxia or capillary bed destruction [4-7].

There is no question that the structure of the pulmonary vasculature is extensively altered in humans and animals chronically exposed to cigarette smoke [8-11]. Alteration of the vasculature can occur extremely quickly after stimulation by either cytokines or flow [12], and there is a rapid proliferative response in the vessel endothelium and wall in both muscular arteries and peribronchiolar arterioles after a brief exposure to cigarette smoke [13]. In addition to this acute effect, a marked increase in the degree of muscularization of the small peribronchiolar vessels, with no increase in intima or muscular wall in the larger and more proximal muscular arteries was found using the guinea-pig model; this process appeared to be independent of emphysematous airspace enlargement, degree of airflow obstruction and presence of increased pulmonary arterial pressure $[5,14]$. Since the group with increased pulmonary arterial pressure had an altered induced pressure-flow relationship, it was suggested that there was dynamic alteration of the vasculature with an increased basal vessel tone secondary to vascular mediators. Cigarette smoke may contain or induce these mediators; smoke is known to contain large concentrations of oxidants [15], and it is possible that, in addition to inducing a proliferative response [16], it exerts a direct constrictive effect on the pulmonary vasculature, or can alter the contractility of arterial smooth muscle cells by interfering with the nitric oxide endothelin relationship [17].

The aim of the present study was to determine whether cigarette smoke would directly alter the dynamic response of the muscular pulmonary arteries. Specifically, the animal model was used to investigate whether the pulmonary arterial vasculature of animals which were either acutely or chronically exposed to cigarette smoke would be either 
more sensitive, or respond to a greater degree, to a contractile stimulus. In addition, since acute smoke exposure is known to produce proliferation in the vasculature, particularly the arterioles in the airway compartment adjacent to the alveolar ducts $[13,18]$, it was an aim to ascertain whether chronic cigarette smoke exposure would induce vascular deoxyribonucleic acid (DNA) synthesis, indicative of cell proliferation, as it is possible that the initial proliferative response would be abrogated by feedback regulatory systems. If chronic cell proliferation existed, the identification of any relationship between the degree of vascular cell proliferation and vascular reactivity was to be determined.

\section{Methods}

Both experimental protocols utilized male Hartley strain guinea-pigs obtained from Charles River (Quebec, Canada), with three animals in each of the test and control groups. To conserve animals, a power analysis was performed based on previous experiments in which a 3-month exposure to cigarette smoke produced an increase in muscularization of the vessels adjacent to the alveolar ducts [5]; the degree of muscularization, and the co-efficient of variation were such that a power analysis allowed for a group size of three animals.

In the first, short-term, experiment, the animals weighed (mean \pm SD) $453 \pm 37$ and $443 \pm 33$ g, respectively, and were $\sim 12$ weeks old. The test group was exposed to the whole smoke of seven cigarettes using the standard nose-only exposure chamber [4], while the control animals were sham smoked. This dose of smoke has been chosen since it produces a carboxyhaemoglobin of $\sim 5 \%$, values similar to those found in human cigarette smokers [19], and also produces airflow obstruction and pulmonary vascular alteration in animals after chronic exposure. The cigarettes used were purchased through the Canada Tobacco Manufacturers' Council, (Montreal, Quebec, Canada) were nonfilter tipped, and were blended to yield $16 \mathrm{mg}$ of tar, $1.1 \mathrm{mg}$ of nicotine and $11 \mathrm{mg}$ of carbon monoxide when smoked to a $23-\mathrm{mm}$ butt length.

In the second experiment, the test animals weighed $46328 \mathrm{~g}$ at the commencement of exposure while the control animals weighed $45939 \mathrm{~g}$; at the termination of the experiment, the smoke exposed animals weighed $822133 \mathrm{~g}$ while the control animals weighed $98361 \mathrm{~g}$ (values not significantly different). In this protocol, the test animals were exposed to the smoke of seven cigarettes each day, 5 days each week for a total of 4 months; control guinea-pigs were sham smoked. The 4 month period was chosen since previous experiments have shown that animals exposed to smoke for this length of time developed structural alterations in the pulmonary vasculature [5]. In order to label cells synthesizing DNA, each animal received an intravenous injection of $60 \mathrm{mg} \cdot \mathrm{kg}^{-1}$ 5 bromo-2'-deoxyuridine (BrdU; Boehringer-Mannheim, Laval, Quebec, Canada) in phosphate buffered saline (PBS) vehicle, $3 \mathrm{~h}$ prior to sacrifice.

\section{Explant preparation}

Explants were prepared using a slight modification of the method of SHI et al. [20]. All animals were sacrificed $24 \mathrm{~h}$ post-smoke or sham exposure, using anaesthesia with intraperitoneal urethane $\left(0.5 \mathrm{~g} \cdot \mathrm{kg}\right.$ weight $\left.{ }^{-1}\right)$, and exsanguination through a catheter placed in the vena cava. The anterior chest wall was removed, and in the second protocol the left lung was clamped and removed prior to flushing the vasculature of the right lung with 10 $\mathrm{mL}$ of heparinized Ringer's solution; the vasculature of both lungs was flushed in the first protocol. The lung block was then removed, the trachea cannulated, and the lungs inflated with $1 \%$ agarose in bicarbonate buffered culture medium (BCM) at $37^{\circ} \mathrm{C}$ to near total lung capacity and cooled for $30 \mathrm{~min}$ at $40^{\circ} \mathrm{C}$.

The lungs were then placed in a small chamber; using a hand-held microtome blade, sections $0.5-1 \mathrm{~mm}$ in thickness were obtained. Explant sections which appeared to contain at least one vessel in cross-section were placed in a $60 \&$ times; $15 \mathrm{~mm}$ culture well containing $3 \mathrm{~mL}$ of BCM and incubated overnight at $37^{\circ} \mathrm{C}$ in air enriched to $5 \%$ $\mathrm{CO}_{2}$.

\section{Image acquisition}

The lung explants were transferred to a Lab-Tec chamber slide (Nunc Inc, Naperville, IL, USA) containing 300 $\mu \mathrm{L}$ of N-2-hydroxyethylpiperazine-N-2-ethanesul nic acid (HEPES)-buffered culture medium (HCM), and placed on the stage of a computer linked inverted microscope. The small arteries adjacent to bronchioles were identified, and baseline images photographed through a video camera (JVC TK-107; JVC, Tokyo, Japan) and recorded on computer disk. Vessels $1,000-100 \mu \mathrm{m}$ in diameter could be measured accurately. As the preliminary experiments had not shown any response of the vessels to a nitric oxide generator, the vessels were assumed to have a minimal baseline tone. To deliver the appropriate concentrations of constrictor, the methodology of SHI et al. [20] was used; $50 \mu \mathrm{L}$ of $10^{-9} \mathrm{M}$ histamine in HCM was added directly onto the surface of the explants, and $20 \mathrm{~s}$ later (the time of the peak response), images of the vessels were again obtained. After a 2-min interval, this procedure was again repeated for each concentration of histamine $\left(10^{-7}, 10^{-5}\right.$, $\left.10^{-3} \mathrm{M}\right)$. After each dose, $50 \mu \mathrm{L}$ of liquid was taken out of the well in order to maintain a total solution of $300 \mu \mathrm{L}$ in the chamber [21]. After completion of the dose response curves, the stored images were printed, and lumen area and perimeter measured using a Bioquant ${ }^{\mathrm{TM}}$ (R\&M Biometrics, Nashville, TN, USA) morphometric analysis system.

\section{Bromodeoxyuridine analysis}

The assay was performed according to a previously published protocol [13]. In brief, the left lungs were removed and inflated to $25 \mathrm{cmH}_{2} \mathrm{O}$ pressure with $4 \%$ cold fresh paraformaldehyde. The lungs were sectioned after $7 \mathrm{~h}$, and a midsagittal slice was dehydrated, embedded in paraffin, and sections cut at $4 \mu \mathrm{m}$ thickness. The deparaffinized lung sections were trypsinized with $0.05 \%$ trypsin in $0.5 \mathrm{~m}$ tris-hydroxymethyl-amino methane (Tris)$\mathrm{HCl} \mathrm{pH} 8.0$ for $10 \mathrm{~min}$, washed with PBS, and endogenous peroxidase blocked with $0.3 \% \mathrm{H}_{2} \mathrm{O}_{2}$ in methanol. Nuclei which had incorporated $\mathrm{BrdU}$ were visualized by overnight treatment at $4{ }^{\circ} \mathrm{C}$ with mouse anti-BrdU (Boeringer-Mannheim) diluted 1:80. Sections were then washed in PBS, and the secondary antibody (mouse 
immunoglobulin (Ig)G; Vector Laboratories, (Burlingame, CA, USA) applied. After a final wash, the sections were incubated with aminoethylcarbazole (AEC) for 10 min to produce a visible product. A light haematoxylin counterstain was utilized for nuclear identification. All pulmonary arteries adjacent to the bronchioles, and all of the small arterial vessels adjacent to the alveolar ducts were examined. The fraction of staining nuclei was determined by counting, at $\times 1,000$ magnification, all of the stained and unstained nuclei in the arterial endothelium and arterial wall. It has been previously shown [13] that neither macrophages nor acute inflammatory cells are found in significant numbers in the vessel endothelium or wall; the proliferating cells in the wall are therefore of muscle or fibroblastic origin.

\section{Vascular structure}

A section from the paraffin block was stained with aldehyde fuchsin elastic stain, and the muscularization of the pulmonary arterioles and small arteries was assessed using the method of HunTER et al. [22]. This method defines a muscularized arteriole as one which has a double elastic lamina, and is based on the concept that as the muscle develops, so does an internal elastic lamina. Twenty random fields were examined, and the number of small arteries/arterioles adjacent to the alveolar ducts in each field counted, excluding muscular arteries adjacent to membranous or respiratory bronchioles. These vessels measured $35-10 \mu \mathrm{m}$ in diameter. Each vessel was then examined under $\times 100$ oil immersion to determine whether it had a double elastic lamina. A vessel was counted as positive only if the elastic lamina was double for at least $50 \%$ of the circumference.

\section{Statistics}

All analyses were performed using the SYSTAT system (SYSTAT Inc., Evanston, IL, USA) [23]. The values for explant vessel lumen area were expressed as a percentage of the baseline values. Comparisons between the smoke exposed and control vascular reactivity data and the reactivity data of the acutely and chronically exposed animals were performed using a Kolmogorov-Smirnov analysis for nonparametric data. Using influence plots, the DNA synthesis data were first examined to make sure that no one animal influenced the group data. Since there was no single animal which had undue influence, the data were combined, and the groups compared using the nonparametric Kruskal-Wallis analysis. The percentage of muscularized arteries/arterioles, using a single value for each animal, was compared between groups utilizing an one way analysis of variance, and data are expressed as mean \pm SD.

\section{Results}

\section{Lung explants}

To assess the reactivity of the vessels to increasing histamine concentrations in the animals which received a single exposure to cigarette smoke $24 \mathrm{~h}$ prior to sacrifice, 29 arteries in the explants from the control animals and 29 arteries in the explants from the smoke exposed animals were examined. The data indicated that there was no difference between the vascular reactivity in the smoke exposed group compared to the control, nonexposed, animals. After treatment with increasing concentrations of histamine $\left(10^{-9}-10^{-3} \mathrm{M}\right)$, the control arteries contracted to $98 \pm 3,96 \pm 5,74 \pm 16$ and $62 \pm 15 \%$ of the baseline area, respectively. The animals which had received a single exposure to smoke contracted to $102 \pm 6,99 \pm 8,85 \pm 14$, and $72 \pm 15 \%$ of the baseline area, respectively.

To assess the reactivity in the animals which were exposed to smoke or sham smoke for 4 months; 25 arteries in the explants from the control animals and 28 arteries in the explants from the smoke exposed animals were examined. No difference in the reactivity between the groups was found. After treatment with increasing concentrations of histamine $\left(10^{-9}-10^{-3} \mathrm{M}\right)$, the control arteries contracted to $98 \pm 3,96 \pm 5,91 \pm 8$ and $84 \pm 11 \%$ of the baseline area respectively. The animals which had received daily exposure to smoke for four months contracted to $99 \pm 4,97 \pm 6$, $88 \pm 9$ and $80 \pm 9 \%$ of the baseline area respectively.

Because it was possible that vascular contractility was altered by age, comparisons between the control groups of the acutely exposed and chronically exposed animals who were some 4 months older were performed. This analysis showed that the older animals had a lesser degree of contraction at the higher concentrations $\left(10^{-5}\right.$ and $\left.10^{-3} \mathrm{M}\right)$ of histamine (each comparison $\mathrm{p}<0.01$ ).

\section{Deoxyribonucleic acid synthesis}

These data are highly skewed, and as it is the distribution of the data, rather than mean or median values which is important in this analysis, these data have been illustrated using multiple histograms, as shown in figures 1 and 2 . Nineteen vessels adjacent to the bronchioles in the control animals, and 22 in the smoke exposed animals were examined; 37 vessels adjacent to the alveolar ducts were studied in the control animals compared to 36 in the smoke exposed animals. Figure 3 illustrates BrdU staining in the endothelium and muscular wall of a vessel adjacent to an alveolar duct. The peribronchiolar vessel wall cells in the smoke exposed animals had a significantly increased percentage of labelled cells $(\mathrm{p}<$ 0.001 ) compared to the control animals. Although the endothelial cells of the peribronchiolar vessels in the smoke exposed animals had a tendency to have increased labelling, this did not reach statistical significance. In the small vessels adjacent to the alveolar ducts, the smoke exposed animals had an increased percentage of labelled cells in both the vessel wall $(p<0.001)$ and the endothelial cells $(\mathrm{p}<0.01)$.

\section{Vascular structure}

A total of $20 \pm 1$ vessels per animal in the control animals, and $17 \pm 4$ per animal in the smoke exposed animals were examined; $34.7 \pm 7.6 \%$ of the control vessels had double elastic laminae, compared to $62.7 \pm 5.5 \%$ of 

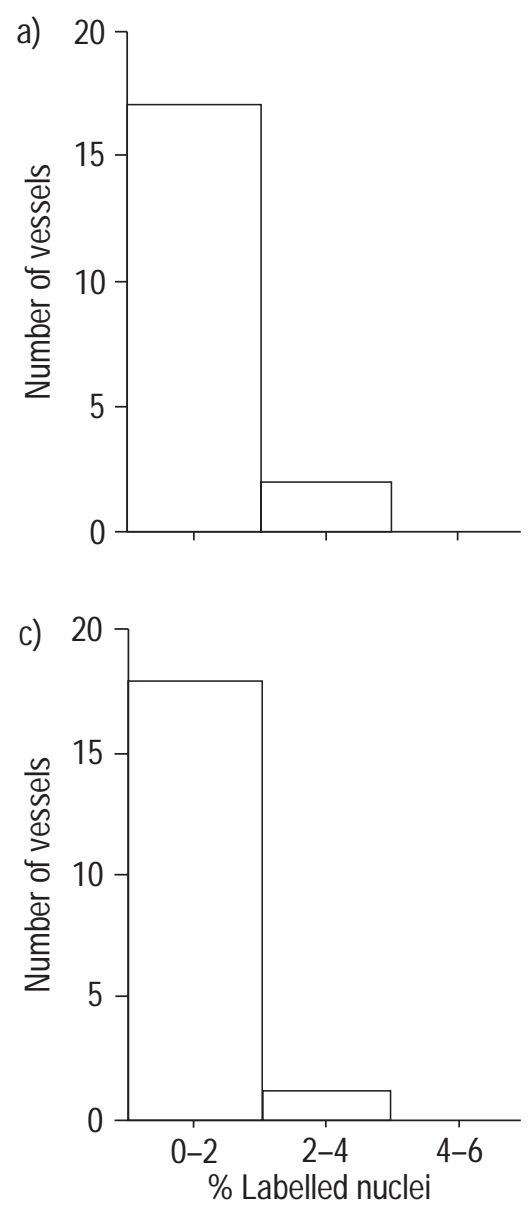

b)

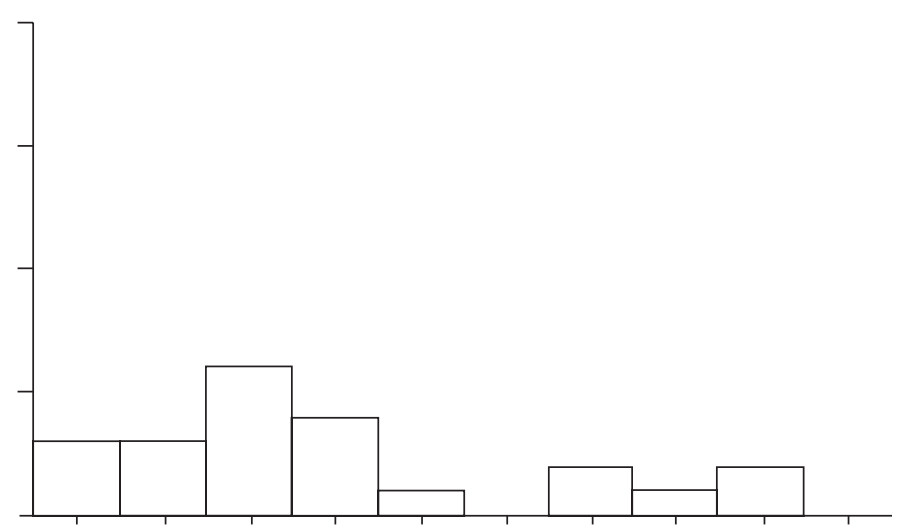

d)

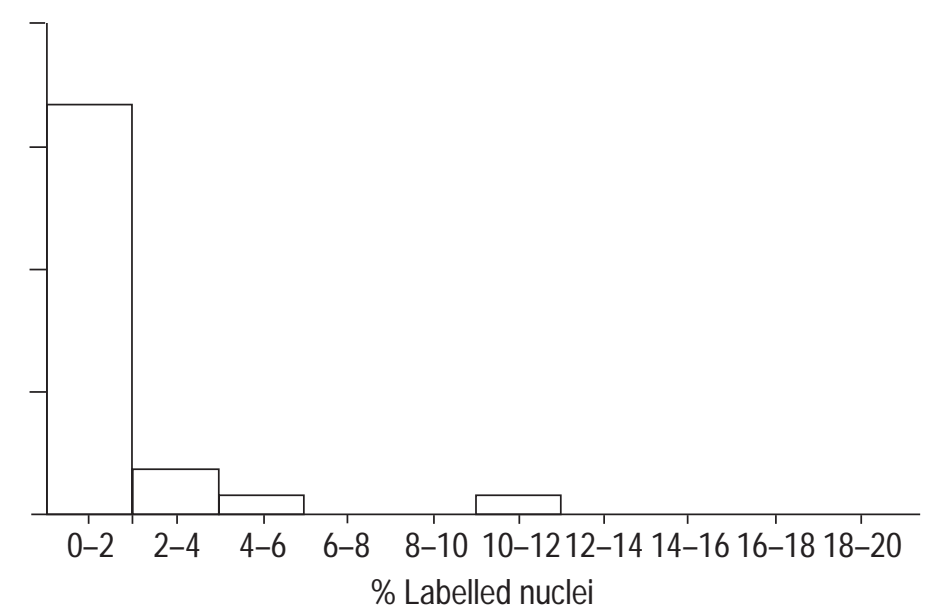

Fig. 1 - a histogram based on the percentage of nuclei labelled with 5-bromo- 2 '-deoxyuridine (BrdU) in cellular compartments of the arteries adjacent to the bronchioles. a) Percentage of labelled nuclei in the vessel wall cells of control animals; b) percentage of labelled nuclei in vessel wall cells of the animals exposed to cigarette smoke for 4 months; c) percentage of labelled nuclei in the endothelial cells of control animals; d) percentage of labelled nuclei in the endothelial cells of the animals exposed to cigarette smoke for 4 months.

vessels in the smoke exposed group $(\mathrm{p}<0.01)$. Figure 4 illustrates a muscularized arteriole.

\section{Discussion}

In the authors' laboratory, a model of cigarette smoke induced pulmonary disease which includes both pulmonary vasculature and airspace alteration has been developed [5], and has been utilized to try to understand the mechanism of the development of pulmonary hypertension in cigarette smokers. It has been shown that the animals were not systemically hypoxic [5], and that, although there appeared to be a relationship between the presence of airflow obstruction and increased pulmonary arterial pressure, there was no relationship between the presence of emphysema and the presence of pulmonary hypertension [14]. When microvascular casts of the lungs from guinea-pigs chronically exposed to smoke were examined [7], alterations in capillary network structure was found, but no evidence of capillary destruction in the smoke exposed animals; there were no correlations of the structural alterations with the vascular physiology, data consist with the hypothesis that there was a dynamic as well as a structural alteration of the vasculature.
In a previous study (14), It has been found that guineapigs which had developed pulmonary hypertension had a different pulmonary artery pressure response to induced increases in blood flow, and it was concluded that the group which had pulmonary hypertension had an increased baseline tone in the pulmonary vascular tree, but that these vessels could still respond appropriately to increased blood flow. Interestingly, there are also human data which would suggest that vascular resistance can increase without changes in cardiac output in patients with chronic obstructive pulmonary disease [24-26]. It has been speculated that the increased basal tone in the vasculature in the smoke exposed animals might be the result of an increased response to contractile stimuli such as oxidants in cigarette smoke or smoke induced cytokine mediators.

To investigate this possibility, the present study utilized the original technique of SHI et al. [20]. It is important to note that the area of the vessels at baseline in the present study was similar in both control and smoke exposed animals; any increase in basal tone was not reflected by vascular constriction. While this study has shown that the muscular arteries in animals exposed either acutely or chronically to cigarette smoke have neither increased sensitivity nor increased responsiveness to constrictor agents, it remains possible that exposure to smoke will 

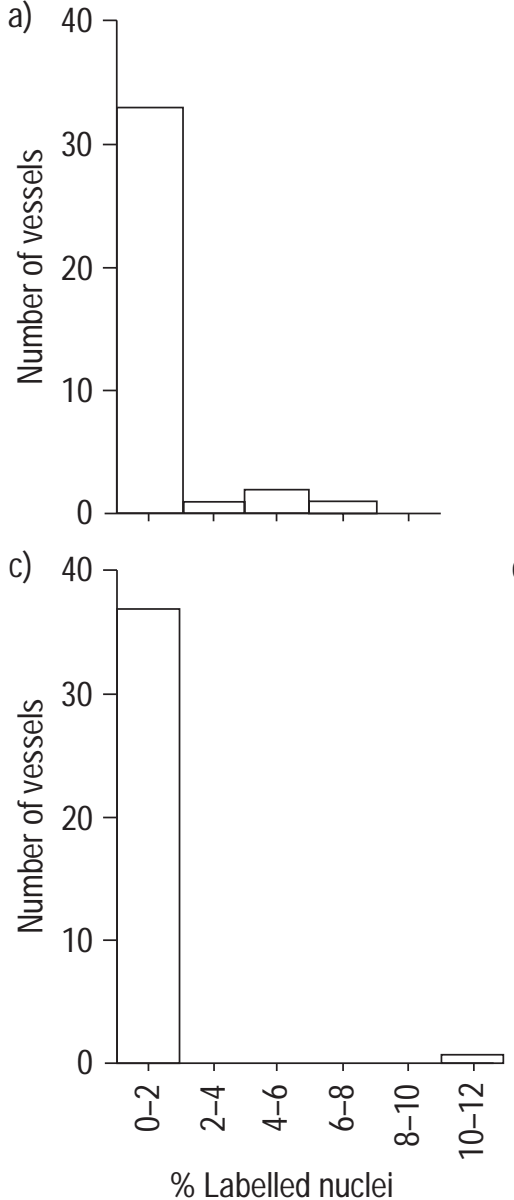

b)

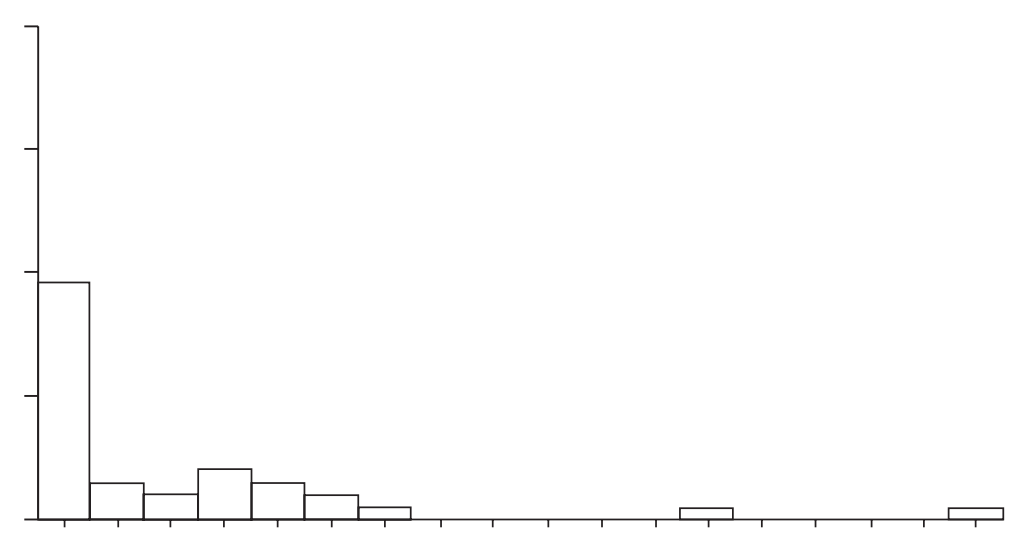

d)

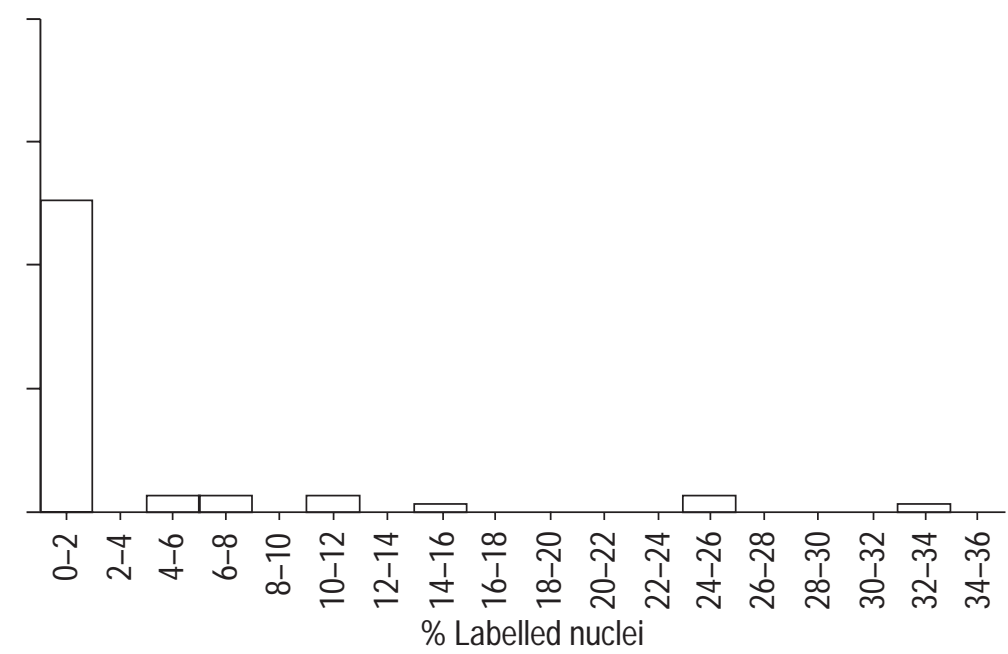

Fig. 2 - a histogram based on the percentage of nuclei labelled with 5-bromo- 2 -deoxyuridine (BrdU) in cellular compartments of the arteries adjacent to the alveolar ducts. a) Percentage of labelled nuclei in the vessel wall cells of control animals; b) percentage of labelled nuclei in vessel wall cells of the animals exposed to cigarette smoke for 4 months; c) percentage of labelled nuclei in the endothelial cells of control animals; d) percentage of labelled nuclei in the endothelial cells of the animals exposed to cigarette smoke for 4 months.

alter the ability of the vessels to respond to dilators. Although there have been relatively few studies which have examined vascular constriction, several studies have shown that both the systemic and pulmonary vasculature in smokers has an impaired relaxation response, which appears to be related to alterations in structure [27-32]. KIOWSKI et al. [30] examined the peripheral vasculature of smokers, and found that while short term smoking was associated with an enhanced endothelin induced vasoconstriction, the vessels in the chronically exposed smokers had impairment of the endothelial control of vascular tone. DinH-XUAN and coworkers [27, 28] worked with pulmonary artery rings and demonstrated that vessels from patients with chronic obstructive pulmonary disease (COPD) had $50 \%$ of the degree of induced relaxation found in control vessels. The degree of relaxation correlated negatively with the severity of intimal thickening in the vessels, and the production of nitric oxide in the vessels appeared impaired. Impairment of nitric oxide mediated, endothelium-dependent relaxation was found as well in the vessels of patients wIth COPD by PEINADO et al. [33], who also observed a correlation between maximal relaxation and forced expiratory volume in one second (FEV1)/ forced vital capacity (FVC)\% predicted.
In the 12 week old control animals, similar degrees of arterial contractility to those of SHI et al. [20] were obtained; these investigators used histamine or 5-hydroxytryptamine as primary constrictors. The 7 month old control animals, however, had a much lower constrictor response. In a subsequent study, SHI et al. [34] found that contractile responses could be altered by the presence of endothelium-derived factors. Since histamine does stimulate endothelial nitric oxide release [35], it is possible that the vessels of the older animals in the present study had enhanced nitric oxide release. However, in that both the control and smoke exposed animals had similar contractile patterns, and smoke exposure did not affect the response of these vessels to the contractile effects of histamine, it is concluded that it is unlikely that chronic smoke exposure has altered the ability of these vessels to constrict.

The pulmonary vasculature can be divided into several structural compartments, and this study has examined only the compartments adjacent to the bronchioles (muscular arterial compartment) and adjacent to the alveolar ducts (arteriolar compartment). It remains possible that vessels of the size that can be examined using the explant technique are not the main site of vascular contractility in the smokeexposed guinea-pig. Although the vessels adjacent to the 


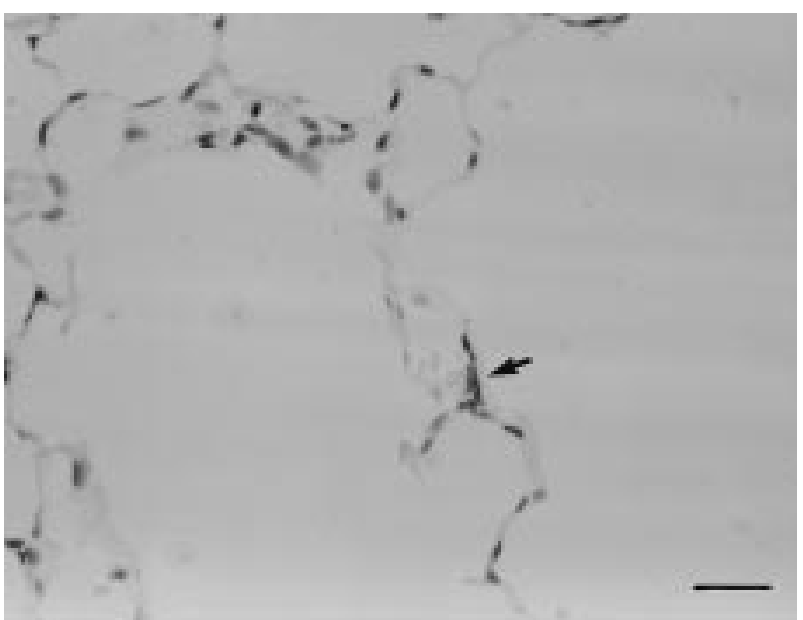

Fig. 3 - A muscularized arteriole which demonstrates 5-bromo-2'deoxyuridine (BrdU) staining in the nuclei of the endothelial cells (arrow). BrdU haematoxylin stain, original magnification $\times 650$. Internal scale bar $=15 \mu \mathrm{m}$.

membranous bronchioles can be analysed using explants, it is not possible to examine the vessels adjacent to the alveolar ducts. The DNA synthesis data indicate that chronic smoke exposure causes increased activity in the walls of the arteries adjacent to the membranous bronchioles, but there is also marked proliferative response in both the endothelial and wall cells of the muscular vessels adjacent to the alveolar ducts. Furthermore, an increased percentage of vessels in this area with a double elastic lamina was found, indicative of increased muscularization and ultimate arterialization, data which are in agreement with those of a previous study [5].

Increased proliferative activity has been found previously after acute exposure to cigarette smoke in vivo [13] and cigarette smoke components in vitro $[36,37]$. While some of the proliferation appears to be related to activation of the nicotinic receptor [36], it has also been shown that at least part of the proliferative activity appears to be mediated via the endothelin A receptor [18] and through oxidant-antioxidant imbalance [16]. How-

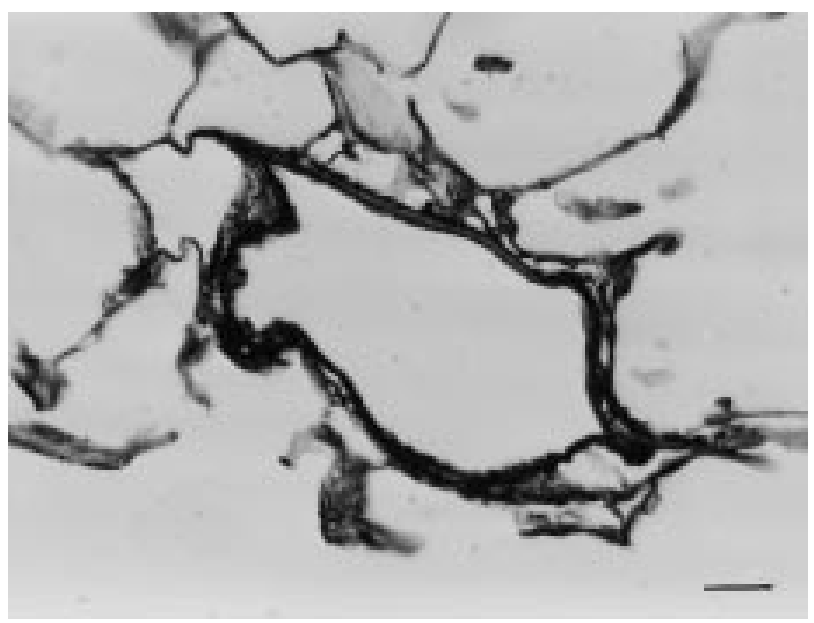

Fig. 4 - A muscularized arteriole. Note the prominent double elastic lamina which extends almost the entire circumference. Aldehyde fuchsin elastic stain, original magnification $\times 650$. Internal scale bar $=15 \mu \mathrm{m}$. ever, the present study is the first to confirm that DNA synthesis appears to continue with chronic smoke exposure. It is possible that it is this continuing proliferative response which has resulted in the muscular media hyperplasia of the arterioles adjacent to the alveolar ducts.

In summary, chronic cigarette smoke exposure will produce increased deoxyribonucleic acid synthesis in the pulmonary arteries and arterioles, and this is associated with increased muscularization of the vessels adjacent to the alveolar ducts. The deoxyribonucleic acid synthesis in the walls of the vessels adjacent to the bronchioles is not, however, associated with any increased contractile response.

\section{References}

1. Williams I, Boyd MJ, Humberstone AM, Wilson AG, Millard FJC. Pulmonary arterial hypertension and emphysema. Brit J Dis Chest 1984; 78: 211-216.

2. Staub NC. Site of hypoxic pulmonary vasoconstriction. Chest 1985; 88: 240S-245S.

3. Reid LM. Structure and function in pulmonary hypertension. Chest 1986; 89: 279-288.

4. Wright JL, Churg A. Cigarette smoke causes physiologic and morphologic changes of emphysema in the guinea pig. Am Rev Respir Dis 1990; 142: 1422-1428.

5. Wright JL, Churg A. Effect of long-term cigarette smoke exposure on pulmonary vascular structure and function in the guinea pig. Exp Lung Res 1991; 17: 997-1009.

6. Yamato H, Sun J, Churg A, Wright JL. Cigarette smokeinduced emphysema in guinea pigs is associated with diffusely decreased capillary density and capillary narrowing. Lab Invest 1996; 75: 211-219.

7. Yamato H, Sun J, Churg A, Wright JL. Guinea pig pulmonary hypertension caused by cigarette smoke cannot be explained by capillary bed destruction. $J$ Appl Physiol 1997; 82: 1644-1653.

8. Hale KA, Niewoehner DE, Cosio MG. Morphologic changes in the muscular pulmonary arteries: relationship to cigarette smoking, airway disease, and emphysema. Am Rev Respir Dis 1980; 122: 273-278.

9. Wilkinson M, Langhorne CA, Heath D, Darer GR, Howard P. A pathophysiological study of 10 cases of hypoxic cor pulmonale. Quart J Med 1988; 249: 65-85.

10. Magee F, Wright JL, Wiggs BR, Pare PD, Hogg X. Pulmonary vascular structure and function in chronic obstructive pulmonary disease. Thorax 1988; 43: 183-189.

11. Wright JL, Petty TL, Thurlbeck WM. Analysis of the structure of the muscular pulmonary arteries in patients with pulmonary hypertension and COPD: National Institutes of Health Nocturnal Oxygen Therapy Trial. Lung 1992; 170: 109-124.

12. Langille BL. Remodeling of developing and mature arteries: endothelium, smooth muscle, and matrix. J Cardiovasc Pharm 1993; 21 (Suppl 1): S11-S17.

13. Sekhon HS, Wright JL, Churg A. Cigarette smoke causes rapid cell proliferation in small airways and associated pulmonary arteries. Am J Physiol 1994; 267: L557-563.

14. Wright JL. The relationship of increased pulmonary artery pressure and airflow obstruction to emphysema. J Appl Physiol 1993; 74: 1320-1324.

15. Church DF, Pryor WA. Free-radical chemistry of cigarette smoke and its toxicological implications. Environ Hlth Perspect 1985; 64: 111-126.

16. Wright JL, Sun J, Churg A. Glutathione levels play a role 
in cigarette smoke induced cell proliferation in the rat lung. Inhalation Toxicology 1998; 10: 969-994.

17. Zellers TM, McCormick J, Wu Y. Interaction among ET1, endothelium-derived nitric oxide, and prostacyclin in pulmonary arteries and veins. Am J Physiol 1994; 267: H139-147.

18. Dadmanesh F, Wright JL. Endothelin-A receptor antagonist BQ-610 blocks cigarette smoke-induced mitogenesis in rat airways and vessels. Am J Physiol 1997; 272: L614-618.

19. Prignot J. Quantification and chemical markers of tobacco exposure. Eur J Resp Dis 1987; 701: 1-7.

20. Shi W, Wang C, Dandurand RJ, Eidelman DH, Michel RP. Differential responses of pulmonary arteries and veins to histamine and 5-HT in lung explants of guinea-pigs. Brit J Pharmacol 1998; 123: 1525-1532.

21. Dandurand RJ, Wang CG, Phillips NC, Eidelman DH. Responsiveness of individual airways to methacholine in adult rat lung explants. $J$ Appl Physiol 1993; 75: 364-372.

22. Hunter C, Barer GR, Shaw JW, Clegg EJ. Growth of the heart and lungs in hypoxic rodents: a model of human hypoxic disease. Clin Sc Mol Med 1974; 46: 375-391.

23. Wilkinson L. SYSTAT: the system for statistics. Evanston, Illinois: SYSTAT Inc; 1988.

24. Fletcher EC, Levin DC. Cardiopulmonary hemodynamics during sleep in subjects with chronic obstructive pulmonary disease. Chest 1984; 85: 6-14.

25. Agusti AGN, Barbera JA, Roca J, Wagner PD, Rodriguez-Roisin R. Hypoxic pulmonary vasoconstriction and gas exchange during exercise in chronic obstructive pulmonary disease. Chest 1990; 97: 268-275.

26. Boysen PG, Block AJ, Wynne JW, Hunt LA, Flick MR. Nocturnal pulmonary hypertension in patients with chronic obstructive pulmonary disease. Chest 1979; 76 : 536-542.

27. Dinh-Xuan AT, Higenbottam TW, Clelland CA, et al. Impairment of endothelium-dependent pulmonary-artery relaxation in chronic obstructive lung disease. $N$ Engl $J$ Med 1991; 324: 1539-1547.

28. Dinh-Xuan AT, Pepke-Zaba J, Butt AY, Cremona G, Higenbottam TW. Impairment of pulmonary-artery endothelium-dependent relaxation in chronic obstructive lung disease is not due to dysfunction of endothelial cell membrane receptors nor to L-arginine deficiency. Brit $J$ Pharmacol 1993; 109: 587-591.

29. Cremona G, Dinh-Xuan AT, Higenbottam TW. Endothelium-derived relaxing factor and the pulmonary circulation. Lung 1991; 169: 185-202.

30. Kiowski W, Linder L, Stoschitzky K, et al. Diminished vascular response to inhibition of endothelium-derived nitric oxide and enhanced vasoconstriction to exogenously administered endothelin-1 in clinically healthy smokers. Circ 1994; 90: 27-34.

31. Barbera JA, Riverola A, Roca J, et al. Pulmonary vascular abnormalities and ventilation perfusion relationships in mild chronic obstructive pulmonary disease. Am J Respir Crit Care Med 1994; 149: 423-429.

32. Douglas NJ, Calverley PMA, Leggett RJE, Brash HM. Transient hypoxaemia during sleep in chronic bronchitis and emphysema. Lancet 1979; $1-4$.

33. Peinado VI, Barbera JA, Ramirez J, et al. Endothelial dysfunction in pulmonary arteries of patients with mild COPD. Am J Physiol 1998; 274: L908-913.

34. Shi W, Eidelman DH, Michel RP. Differential relaxant responses of pulmonary arteries and veins in lung explants of guinea-pigs. J Appl Physiol 1997; 83: 1476-1481.

35. Furchgott RF, Vanhoutte PM. Endothelium-derived relaxing and contracting factors. FASEB J 1989; 3: 2007-2018.

36. Villablanca A. Nicotine stimulates DNA synthesis and proliferation in vascular endothelial cells in vitro. $J \mathrm{Appl}$ Physiol 1998; 84: 2089-2098.

37. Nishio E, Watanabe Y. Cigarette smoke extract is a modulator of mitogenic action in vascular smooth muscle cells. Life Sci 1998; 62: 1339-1347. 